\title{
Environment-dependent plasticity and ontogenetic changes in the brain of hatchery- reared Atlantic salmon
}

Näslund, J.; Larsen, Martin Hage; Thomassen, S.T.; Aarestrup, Kim; Johnsson, J. I.

Published in:

Journal of Zoology

Link to article, DOI:

10.1111/jzo.12392

Publication date:

2017

Document Version

Publisher's PDF, also known as Version of record

Link back to DTU Orbit

Citation (APA):

Näslund, J., Larsen, M. H., Thomassen, S. T., Aarestrup, K., \& Johnsson, J. I. (2017). Environment-dependent plasticity and ontogenetic changes in the brain of hatchery-reared Atlantic salmon. Journal of Zoology, 301(1), 75-82. https://doi.org/10.1111/jzo.12392

\section{General rights}

Copyright and moral rights for the publications made accessible in the public portal are retained by the authors and/or other copyright owners and it is a condition of accessing publications that users recognise and abide by the legal requirements associated with these rights.

- Users may download and print one copy of any publication from the public portal for the purpose of private study or research.

- You may not further distribute the material or use it for any profit-making activity or commercial gain

- You may freely distribute the URL identifying the publication in the public portal 


\title{
Environment-dependent plasticity and ontogenetic changes in the brain of hatchery-reared Atlantic salmon
}

\author{
J. Näslund ${ }^{1}$, M. H. Larsen ${ }^{2,3}$, S. T. Thomassen ${ }^{3}$, K. Aarestrup ${ }^{2} \&$ J. I. Johnsson ${ }^{1}$ \\ 1 Department of Biological and Environmental Sciences, University of Gothenburg, Gothenburg, Sweden \\ 2 National Institute of Aquatic Resources, Section for Freshwater Fisheries and Ecology, Technical University of Denmark, Silkeborg, Denmark \\ 3 Danish Centre for Wild Salmon, Randers, Denmark
}

\begin{abstract}
Keywords
plasticity; Salmonidae; aquaculture; stocking; brain development; rearing density; rearing conditions; Salmo salar.
\end{abstract}

\author{
Correspondence \\ Joacim Näslund, Department of Biological and \\ Environmental Sciences, University of \\ Gothenburg, PO Box 463, SE-405 30 \\ Gothenburg, Sweden. \\ Email: joacim.naslund@gmail.com \\ Editor: Jean-Nicolas Volff
}

Received 29 December 2015; revised 30 July 2016; accepted 11 August 2016

\begin{abstract}
Lowered rearing density has repeatedly been shown to increase the performance of hatchery-reared salmonids stocked into natural environments. One possible mechanism for this pattern could be that lower densities enhance brain development, which has been shown to be the case in other hatchery enhancement strategies, like environmental enrichment. Here, we investigated the size of the brain in hatcheryreared Atlantic salmon Salmo salar kept at standard (high) and reduced (low) tank densities. In contrast to our predictions, we found that fish reared at high density had larger dry mass of cerebellum and telencephalon, correcting for body size. No differences were detected for total brain mass. Furthermore, we found that the relative size of both telencephalon and cerebellum, in relation to total brain mass, changed with body size. Cerebellum increased in relative size with increased body size, while the opposite pattern was observed for telencephalon. Overall, these results reveal substantial brain plasticity depending on the surrounding environment as well as ontogenetic adaptive changes in the brain of the Atlantic salmon.
\end{abstract}

doi:10.1111/jzo.12392

\section{Introduction}

Stocking of hatchery-reared salmonids to enhance or re-establish populations has been a common practise in fisheries, conservation and restoration programmes for decades, but the relevance of these programmes has been questioned due to the low survivability of stocked fish as compared to wild conspecifics (Schuck, 1948; Jonsson \& Jonsson, 2011). Particular critique has been directed to the fact that many stocking programmes are more concerned with the number of fish to be stocked rather than their quality and the number of surviving fish (e.g. Johnsson, Brockmark \& Näslund, 2014). The survival rates of stocked individuals are commonly less than half of those of wild fish with the same genetic origin (Jonsson \& Jonsson, 2011). Particularly high mortality rates of hatchery salmonids are seen soon after the release (Saloniemi et al., 2004; Aarestrup et al., 2014; Melnychuk et al., 2014). Consequently, several recent studies have focused on rearing methods aiming to modify the hatchery environment for the production of wild-like fish with higher post-stocking survivability (Brännäs \& Johnsson, 2008; Johnsson et al., 2014). Fish density reduction in the rearing tanks is a promising modification, which repeatedly has been shown to increase the post-release survival of salmonids (Brockmark \& Johnsson, 2010; Brockmark, Adriaenssens \& Johnsson, 2010; Barnes et al., 2013; Kavanagh \& Olson, 2014; Larsen et al., 2016; but also see Clarke, Cameron \& Carmichael, 2013). Improved survival of fish reared at reduced densities is, at least partially, believed to be a consequence of development of higher cognitive capacity as well as expression of behaviours more suited for the natural environment (Brockmark et al., 2010; Johnsson et al., 2014). Lower tank densities may, for instance, provide a social environment where interactions among individuals are more similar to the natural environment, allowing for individual recognition and social learning (Griffiths et al., 2004; Chapman, Ward \& Krause, 2008; Brockmark \& Johnsson, 2010). Lowered densities may also reduce crowding stress and related physiological problems (Ellis et al., 2002; Ashley, 2007; Rosengren et al., 2016).

In hatchery-reared salmonids, studies of brain size have suggested positive effects of environmental enrichment in captive environments (Näslund \& Johnsson, 2016), potentially driven by increased cognitive stimulation and brain cell proliferation in more complex environments (Salvanes et al., 2013). Intraspecific brain size variation in teleost fishes can depend on both genetic inheritance (guppy Poecilia reticulata: Kotrschal et al., 2013; Chen et al., 2015) and the environment (Atlantic salmon Salmo salar: Salvanes et al., 2013; shortfin molly Poecilia mexicana: Eifert et al., 2014), and is possibly associated with cognitive capacity (Kotrschal et al., 2013; but see Healy \& Rowe, 2013). Furthermore, studies in three-spined sticklebacks Gasterosteus aculeatus show that there can be substantial independence in growth among different brain regions, allowing for independent responses to environmental factors through phenotypic plasticity (Noreikiene et al., 2015).

Here, we investigated brain size of hatchery-reared Atlantic salmon sampled from an experiment aimed at investigating postrelease survival of fish reared at normal or reduced density. In this 
experiment, reduced density led to increased survival during seaward migration, when the fish were released into a natural stream just prior to the onset of the physiologically induced migration (see Larsen et al., 2016). We specifically investigated the size of telencephalon and cerebellum as these substructures previously have been shown to be affected by the hatchery rearing environment in salmonid fish (Lema et al., 2005; Kihslinger, Lema \& Nevitt, 2006; Kihslinger \& Nevitt, 2006). The relative sizes of brain substructures are generally associated with the relative importance of the associated functions of the substructures in fish (e.g. Kotrschal, van Staaden \& Huber, 1998; Ito et al., 2007). However, the specific functions of distinct brain substructures are convoluted; in general, specific substructures have multiple functions (Striedter, 2005). Nevertheless, based on multiple lines of evidence, the telencephalon is commonly assumed to govern several cognitive functions (Broglio, Rodriguez \& Salas, 2003; Rodríguez et al., 2006; Ebbesson \& Braithwaite, 2012) and the cerebellum is involved in motor coordination (Kotrschal et al., 1998; Roberts, Dean \& Paul, 2002) as well as some cognitive functions (Rodríguez et al., 2006). We also investigated wholebrain size, as some studies suggest effects of rearing environment on the overall size (Näslund et al., 2012; Brown et al., 2013). We hypothesised that brain growth, in particular telencephalic and/or cerebellar growth, would be affected by social interactions. Based on results from previous studies, lower density was assumed to convey more social stimulation as a consequence of higher potential for individual recognition, resource defence and individual decision making in a less crowded environment (Brockmark et al., 2010; Johnsson et al., 2014). Consequently, we predicted that low-density fish would have larger brains, or larger brain substructures related to cognitive ability previously shown to be positively affected by increased environmental complexity (cerebellum: Kihslinger \& Nevitt, 2006; telencephalon: Kihslinger et al., 2006; Salvanes et al., 2013).

The fish in our study showed bimodal size distribution, which is common in hatchery environments (e.g. Thorpe, 1977; Jonsson \& Jonsson, 2011). At the time of sampling, the fish in the upper modal group, but not in the lower modal group, were generally going through smoltification (the physiological transformation for a life in marine environment) (Larsen et al., 2016). Previous studies have indicated that the brain undergoes major changes during smoltification (Ebbesson \& Braithwaite, 2012). To investigate whether ontogenetic changes in gross brain morphology also occur at this stage, we explored effects of body size on the size of telencephalon and cerebellum in relation to total brain size.

\section{Materials and methods}

Rearing and handling of the fish is described in detail in Larsen et al. (2016). In short, the fish were F1 offspring from 47 females and 27 males, caught in River Storå, Denmark, in autumn 2011. From the fry stage, two density treatments were

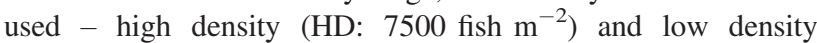
(LD: 2500 fish $\mathrm{m}^{-2}$ ) - each replicated three times in conventional indoor hatchery tanks $(2 \times 2 \mathrm{~m}$, water level $35 \mathrm{~cm})$ (Danish Centre for Wild Salmon, Randers, Denmark). On 16 June 2012, the density of fish was reduced to 1500 fish $\mathrm{m}^{-2}$ and 500 fish $\mathrm{m}^{-2}$ in $\mathrm{HD}$ and $\mathrm{LD}$ tanks respectively. Water temperature (recirculating system, $30 \mathrm{~L} \mathrm{~min}^{-1}$ ) and light regime followed natural cycles.

On 20 March 2013, 12 fish were sampled randomly from each tank (i.e. 36 fish per treatment), euthanized by a benzocaine overdose and decapitated after recording total body length (from the tip of the nose to the end of the spread-out caudal fin; precision: $1 \mathrm{~mm}$ ) and body mass (precision: $0.1 \mathrm{~g}$ ). Heads were preserved in $4 \%$ phosphate-buffered formaldehyde and stored at $4^{\circ} \mathrm{C}$. To facilitate standardized separation of cerebellum from the rest of the brain (as judged from previous pilot dissections of salmonid brains), the heads were dorsoventrally bisected along the midsagittal plane using a scalpel on 25 June 2014 (Fig. 1a).

On 20 July 2015, the brains were dissected out of each half of every head. The cerebellum and telencephalon were separated from the rest of the brain (see Fig. 1). Cerebellum, telencephalon and the rest of the brain (see Fig. 1c) were all separately dried (right and left parts added together) in aluminium foil at $70^{\circ} \mathrm{C}$ for $35 \mathrm{~h}$ and thereafter the dry mass was recorded to the nearest $0.01 \mathrm{mg}$ (Precisa XR 205SM-DR; Precisa Gravimetrics AG, Dietikon, Switzerland).

\section{Statistical analyses}

\section{Whole-brain dry mass}

The dry mass of the whole brain (i.e. telencephalon, cerebellum and the rest of the brain added together; $n_{\mathrm{HD}}=35$, $n_{\mathrm{LD}}=36$ ) was analysed using a general linear model with body length $(L)$ as a covariate and density treatment $(D)$ as a two-level fixed factor. The whole-brain dry mass appeared to have a linear relationship with body length (see Fig. 2) and was consequently not log-transformed. Tank effects were initially tested using tank $(T)$ as a fixed factor nested within $D[T$ $(D)]$. As no tendency for effect was detected $(P>0.9)$, it was subsequently removed from the analysis. The interaction between $D$ and $L(T \times D)$ was also initially included, but not retained in the final model $(P>0.2)$. Residuals from the model were found to be slightly negatively skewed; however, both density groups showed the same distribution pattern and the analysis was therefore retained.

\section{Telencephalon dry mass}

The dry mass of telencephalon $\left(n_{\mathrm{HD}}=36, n_{\mathrm{LD}}=36\right)$ was analysed the same way as the whole brain. No tank effects were detected $(P>0.8)$ and neither were there any evidence of a $T \times D$ interaction $(P=0.24)$. For this reason, these terms were excluded in the final model.

\section{Cerebellum dry mass}

The dry mass of cerebellum $\left(n_{\mathrm{HD}}=35, n_{\mathrm{LD}}=36\right)$ was analysed the same way as the whole brain. No tank effects were detected $(P>0.9)$ and neither were there any evidence of a $T \times D$ interaction $(P=0.12)$. These terms were therefore not included in the final model. 

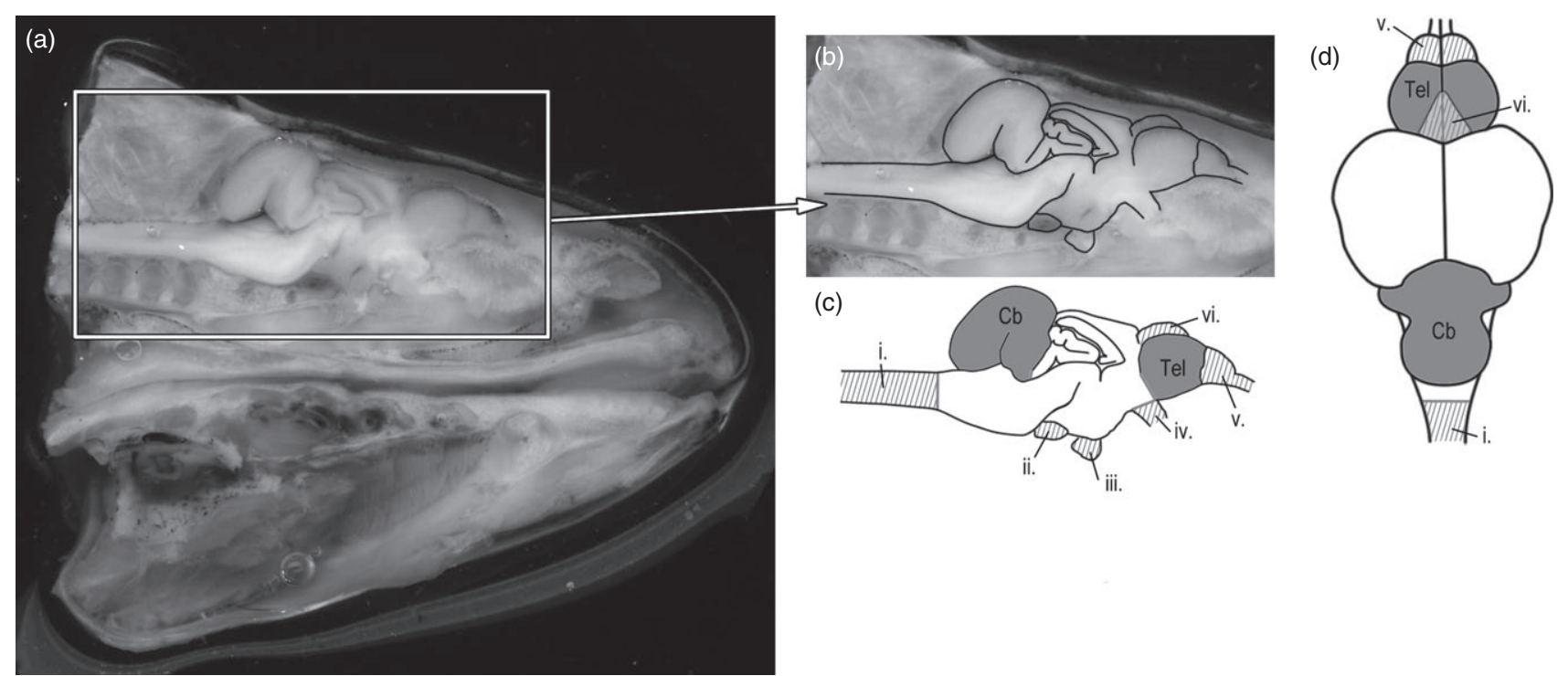

Figure 1 Illustration of the brain dissection scheme. (a) Midsagittal cut through the head of an Atlantic salmon. (b) Outlined main brain substructures. (c) Midsagittal and (d) dorsal schematic illustrations of the brain substructures included (Cb, Tel and 'rest of the brain') and excluded ( $\mathrm{i}-\mathrm{vi}$ ) in the analysis. In grey: $\mathrm{Cb}$ - cerebellum (corpus cerebelli, crista cerebellaris and eminentia granularis, not including valvula cerebellaris); Tel - telencephalon. In white: 'rest of the brain' (i.e. the parts of diencephalon, mesencephalon and rhombencephalon not specifically mentioned; see fig. 15.4a-d in Meek \& Nieuwenhuys, 1998). Striped (excluded): i, medulla spinalis; ii, saccus vasculosus; iii, hypophysis (pituitary gland); iv, nervus opticus; v, bulbus olfactorius and nervus olfactorius; vi, saccus dorsalis and epiphysis (pineal gland). Terminology adapted from Meek \& Nieuwenhuys, 1998.

\section{Size of telencephalon and cerebellum in relation to whole-brain size}

To compare the proportional size of telencephalon and cerebellum in relation to the whole brain, we divided the dry mass of each substructure with the dry mass of the whole brain. The resulting quotients were analysed using the same model and term-selection procedure as in the analyses above. No tank effects were detected $(P>0.35)$ and neither were there any evidence of a $T \times D$ interaction $(P>0.57)$, and consequently these terms were not included.

\section{General notes}

During the dissection and weighing, the experimenter (JN) was blinded with respect to treatment.

All statistical analyses were carried out in IBM SPSS Statistics 22 (IBM Corp., Armonk, NY, USA). Handling, rearing, tagging and sampling of fish were conducted in accordance to the guidelines described in permission (2012-DY-2934-00007) from the Danish Experimental Animal Committee.

\section{Results}

\section{Whole-brain dry mass}

Whole-brain dry mass was strongly positively related to body length $\left(F_{1,68}=1000, P<0.001\right)$, but no effects of density treatment on whole-brain dry mass were detected $\left(F_{1,68}=0.026, P=0.87\right.$ ) (Fig. 2a,b).

\section{Telencephalon dry mass}

Telencephalon dry mass was positively related to body length $\left(F_{1,69}=470, P<0.001\right)$ and found to be higher in the HD treatment $\left(F_{1,69}=5.3, P=0.024\right)$ (Fig. $\left.2 \mathrm{c}, \mathrm{d}\right)$.

\section{Cerebellum dry mass}

Cerebellum dry mass was positively related to body length $\left(F_{1,68}=840, P<0.001\right)$ and found to be higher in the HD treatment $\left(F_{1,68}=4.7, P=0.033\right)$ (Fig. 2e,f).

\section{Size of telencephalon and cerebellum in relation to whole-brain size}

The proportional size of both telencephalon and cerebellum changed with size of the fish $\left(F_{1,68}>45, P>0.001\right)$. The proportional size of telencephalon decreased with size (Fig. 3a) and cerebellum increased with size (Fig. 3b).

In concordance with the previous analyses where body size was corrected for, the HD treatment had relatively larger size of both telencephalon $\left(F_{1,68}=5.9, P=0.018\right.$; Fig. 3a $)$ and cerebellum $\left(F_{1,68}=10, P=0.002\right.$; Fig. $\left.3 b\right)$ when correcting for overall brain size.

\section{Discussion}

The results presented here demonstrate that Atlantic salmon juveniles reared at the higher density had larger cerebella and telencephala as compared to fish reared at the lower density, 
(a)

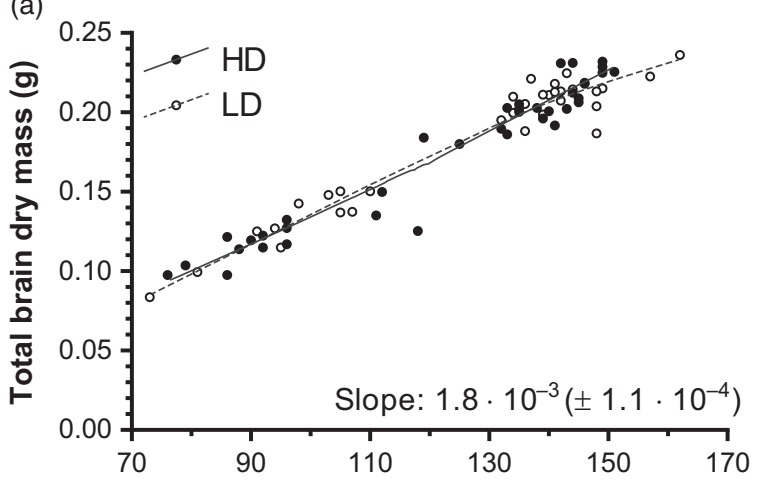

(c)
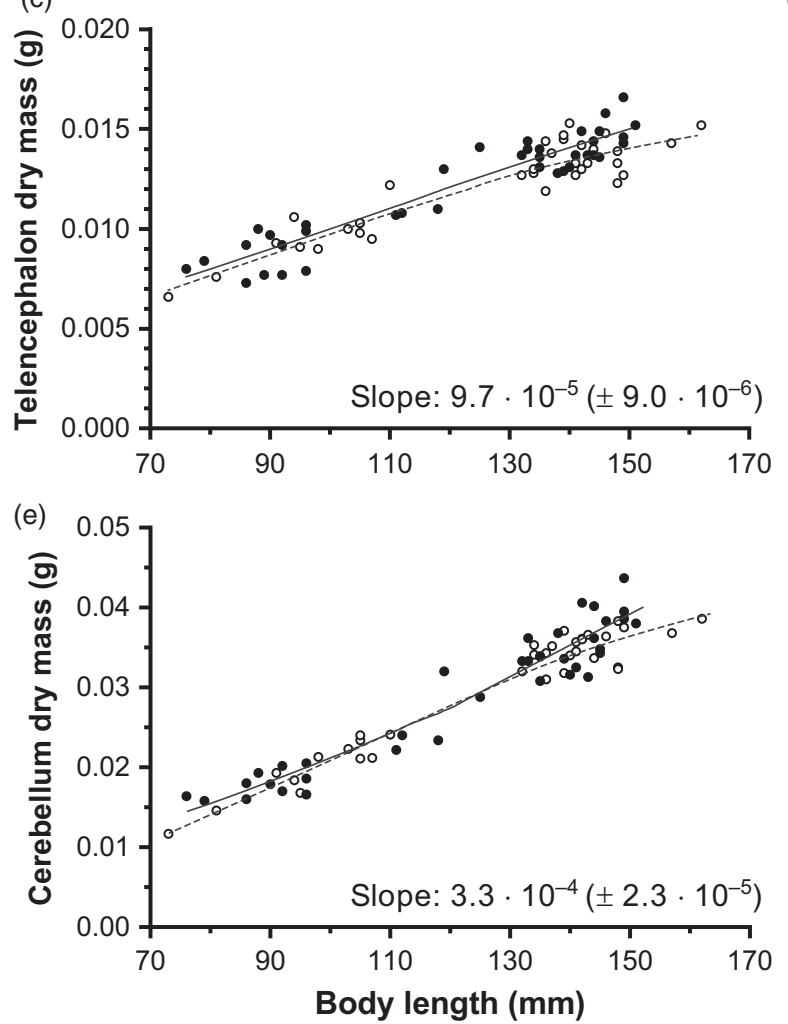

(b)

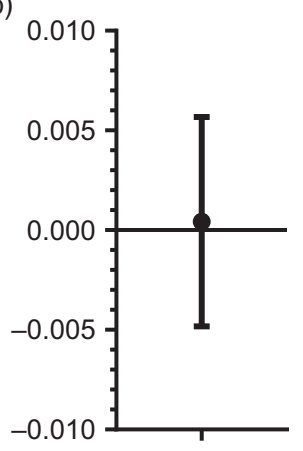

(d)

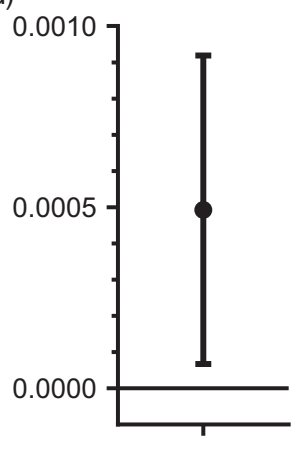

(f)

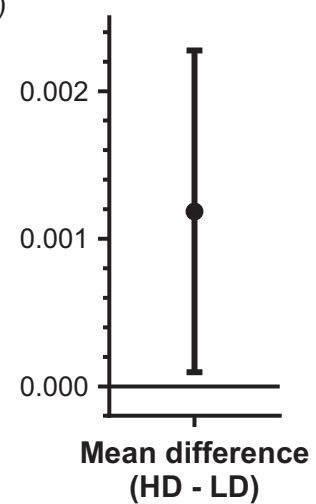

Figure 2 Relationship between body length and (a) total brain, (c) telencephalon and (e) cerebellum dry mass $\times 10$. Plotted lines represent local regressions (LOESS; Epanechnikov kernel, $90 \%$ of points to fit); the general slopes ( $\pm 95 \%$ confidence interval) are parameter estimates for the covariate $L$ (body length) in the linear models (linear regression lines not shown). Mean differences ( $\pm 95 \%$ confidence interval) based on estimated marginal means from linear models are presented in (b), (d) and (f) respectively $(0=$ no difference). HD = high density; $L D=l o w$ density.

both relative to body size and relative to overall brain size. No differences were detected in total brain size between the density treatments. Furthermore, we demonstrate a change in relative mass of cerebellum and telencephalon, compared to total brain mass, with body size. The relative mass of the cerebellum increased with body size, while the relative mass of the telencephalon decreased with size. These latter changes may be related to the smoltification process (Ebbesson \& Braithwaite, 2012).

\section{Rearing environment affects the brain}

Studies on guppies suggest a link between overall brain size and cognitive capacity (Kotrschal et al., 2013). Judging from other studies, both telencephalon and cerebellum are specifically associated with cognition in fish (Salas et al., 1996; Rodríguez et al., 2006; Ebbesson \& Braithwaite, 2012). Regarding environmental effects on cognitive ability, studies on brown trout Salmo trutta have shown that lowered tank 

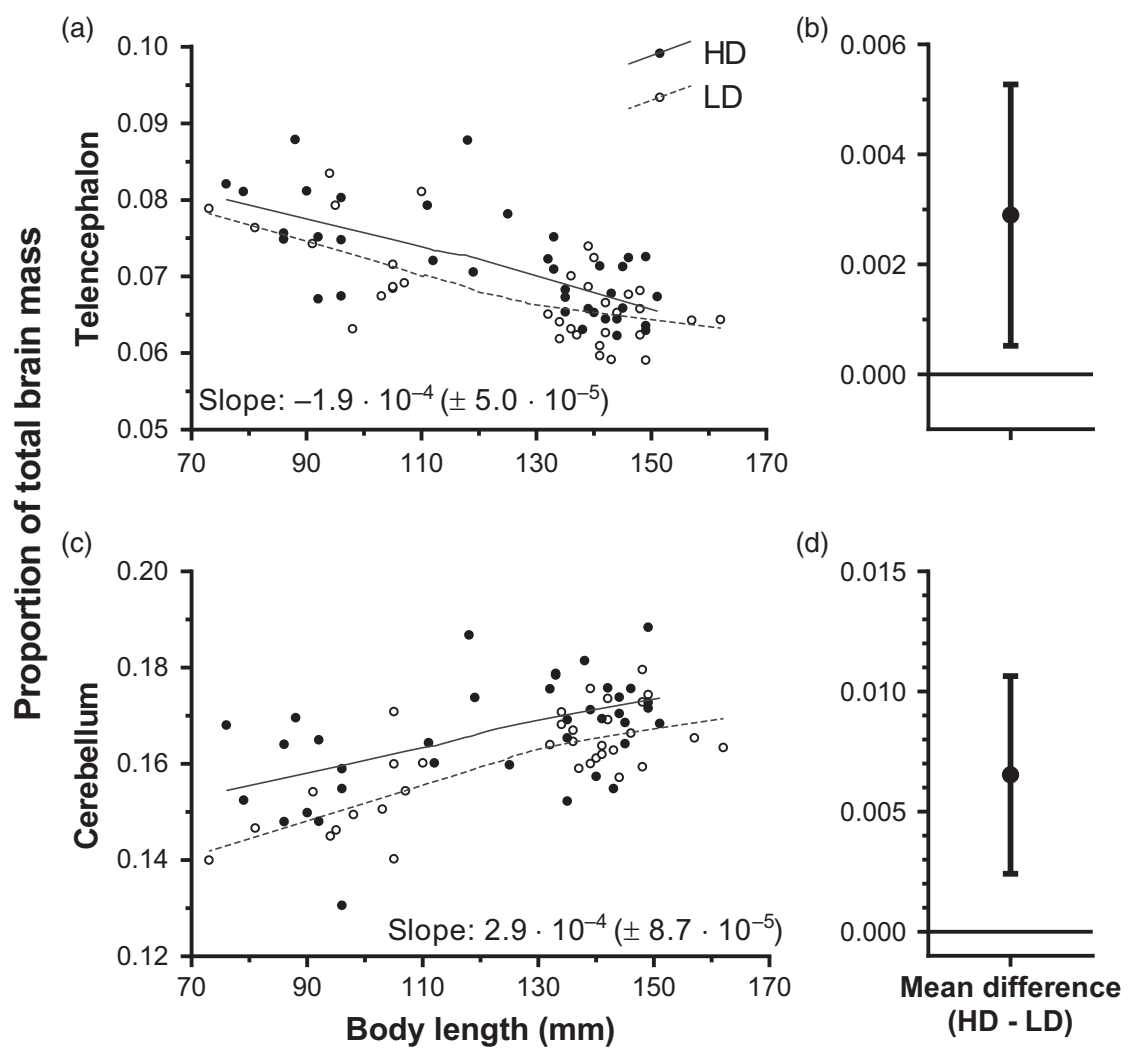

Figure 3 Relationship between body length and (a) proportional dry mass of telencephalon and (c) cerebellum in relation to total brain dry mass. Plotted lines represent local regressions (LOESS; Epanechnikov kernel, 90\% of points to fit); the general slopes ( $\pm 95 \%$ confidence interval) are parameter estimates for the covariate $L$ (body length) in the linear models (linear regression lines not shown). Mean differences $( \pm 95 \%$ confidence interval) based on estimated marginal means from linear models are presented in (b) and (d) respectively $(0=$ no difference).

density could increase cognitive ability (Brockmark et al., 2010) and thus we hypothesised that growth of telencephalon and cerebellum could be stimulated at lower density. However, the results did not support this hypothesis. Instead, we provide contrasting evidence that the average mass of telencephalon and cerebellum of the high-density fish were higher than for low-density fish. We specifically note that the higher migration success of individuals reared in the low-density treatment, demonstrated in Larsen et al. (2016), was neither matched by larger brains nor with larger telencephala or cerebella, which indicates that brain size may not be a suitable indicator of post-release performance.

Interestingly, stocking density in aquaria influence brain size of juvenile daffodil cichlids Neolamprologus pulcher with fish in denser groups developing larger cerebellum and hypothalamus, but smaller tectum opticum and no significant effects on telencephalon, dorsal medulla or bulbus olfactorius (Fischer et al., 2015). Thus, cerebellum growth may be stimulated in higher density environments, perhaps related to increased demands on locomotor performance and manoeuvrability in relation to other individuals (Roberts et al., 2002). However, while the results from Fischer et al. (2015) are partly consistent with our study and thus could suggest some generality of the effects of fish density, direct comparisons could be inappropriate; first, due to group sizes being much lower in the cichlid study, and second, due to the differences in evolutionary history and ecology between the species.

We found no differences in total brain mass, which suggests that there is no general differential energy allocation to brain growth between the density groups, assuming that all brain regions are equally expensive to build. The larger size of cerebellum and telencephalon in the high-density treatments along with the similarity in total brain dry mass between treatments opens for the possibility that other brain substructures than the ones specifically investigated here are relatively larger in lowdensity fish. Potentially, there may be trade-offs in growth among different brain structures, which may give rise to the effects detected here. Additional studies are needed to investigate this.

Studies comparing hatchery-reared fish with wild, or seminaturally reared, fish have provided mixed evidence for the direction of the effects of environment on brain size. In Atlantic cod Gadus morhua, hatchery-reared individuals with wild parentage had lower relative brain mass than wild conspecifics (Mayer et al., 2011). Similar effects have been seen in the salmonid family, of which the Atlantic salmon is a member. For instance, domesticated rainbow trout Oncorhynchus mykiss have been shown to have smaller sizes of several brain 
structures than wild conspecifics (Marchetti \& Nevitt, 2003; Brown et al., 2013). Judging from these studies, the general wild-type brain is larger than the hatchery-type brain, implying that hatchery fish potentially could be maladapted to a natural environment. However, several recent studies have, in contrast, shown that hatchery-reared fish end up with larger relative brain size than conspecifics reared in natural, or semi-natural, environments. For instance, Atlantic salmon individuals being reared continuously in the hatchery (the same hatchery as in the present study) had a higher brain:body mass ratio than individuals that were released into the wild half a year earlier (Näslund et al., 2012). Hatchery-reared chinook salmon Oncorhynchus tshawytscha, originating from wild parents and being released as pre-smolts, were found to have larger relative brain size than wild conspecifics, even after 3 years at sea (Wiper, Britton \& Higgs, 2014). Investigating male clonal lines of rainbow trout, domesticated lines ( $>10$ generations in hatchery) had larger brains than wild lines (wild parents) (Campbell et al., 2015). Furthermore, coho salmon Oncorhynchus kisutch reared in a semi-natural stream channel were found to develop smaller brains than hatchery-reared fish (Kotrschal et al., 2012). In the same study, growth hormone transgenic coho were shown to develop smaller cerebella in the semi-natural channel than in hatchery tanks, which is consistent with the present study since the fish density in the hatchery tanks was lower. Altogether, the evidence for larger brains in wild or semi-naturally reared fish (with respect to both environmental complexity and fish density) is equivocal and requires more investigations.

\section{Ontogenetic effects on the relative size of telencephalon and cerebellum}

We found that the relative size of cerebellum, in relation to the total brain size, increased with body size. This effect could be related to the smoltification, when salmonid fish transform morphology and physiology for a life in marine environments (McCormick, 2013). Heightened levels of neural plasticity and reorganization in the brain have also been repeatedly shown in smoltifying salmonids, albeit mainly in the telencephalon (reviewed in Ebbesson \& Braithwaite, 2012). The size distribution of the experimental population was bimodal, and the upper size mode contained the fish undergoing smoltification, while the lower mode likely contained mainly fish delaying their smoltification to the next year (Thorpe, 1977; Metcalfe, 1998; authors' observations). A previous study on wild brown trout show that anadromous adult individuals have relatively larger cerebella than stream-resident adult individuals (Kolm et al., 2009), which suggests an adaptation to a more mobile life in the marine environment where good manoeuvrability is of high importance to catch prey and avoid predation.

In contrast to the cerebellum, the telencephalon decreased in size relative to the whole brain with increased body size. This effect was not detected in comparisons between anadromous and stream-resident brown trout (Kolm et al., 2009). The apparent difference between these species may, however, be a consequence of their different habitat choice in the sea. Brown trout post-smolts live in coastal areas of the sea, where environmental complexity is a feature of the environment, while Atlantic salmon post-smolts live in a pelagic environment devoid of structural complexity (Jonsson \& Jonsson, 2011). Thus, a reduced size of telencephalon in Atlantic salmon smolts may be a consequence of reduced need for cognitive capacity in a pelagic marine environment being less complex than stream or coastal environments (see e.g. Shumway, 2008).

\section{Conclusions}

We conclude that higher stocking density in hatchery tanks results in larger sizes of telencephalon and cerebellum in the salmon brain. As a consequence of this result, we put forward the new hypothesis that growth of these structures may be stimulated in a high-density environment as a consequence of higher demand for manoeuvrability and increased cognitive demands. We also show that the relative size of telencephalon and cerebellum changes with body size, which could be an effect of smoltification in larger fish. Overall, the results add to previous evidence showing that there is substantial brain growth plasticity in fish depending on the surrounding environment and developmental stage. Results also suggest that increased post-release performance of salmon reared at the lower density may not be due to larger total brain size or larger cerebellum or telencephalon size.

\section{Acknowledgements}

The authors are grateful to the staff at The Danish Centre for Wild Salmon, Randers, Denmark, for fish care during rearing. We also thank the anonymous reviewers of the manuscript for their constructive comments. This study was conducted as part of the strategic project SMOLTPRO, financed by the Swedish Research Council Formas. J.I.J. was also financed by the by the Interreg-project MarGen.

\section{Data accessibility statement}

Data for the experiment are available from the figshare database http://dx.doi.org/10.6084/m9.figshare.3750675.

\section{References}

Aarestrup, K., Baktoft, H., Koed, A., Del Villar-Guerra, D. \& Thorstad, E.B. (2014). Comparison of the riverine and early marine migration behaviour and survival of wild and hatcheryreared sea trout Salmo trutta smolts. Mar. Ecol. Prog. Ser. 496, 197-206.

Ashley, P.J. (2007). Fish welfare: current issues in aquaculture. Appl. Anim. Behav. Sci. 104, 199-235.

Barnes, M.E., Wipf, M.M., Domenici, N.R., Kummer, W.M. \& Hanten, R.P. (2013). Decreased hatchery rearing density improves poststocking harvest and return to spawning of landlocked fall Chinook salmon. N. Am. J. Aquac. 75, 244250 . 
Brännäs, E. \& Johnsson, J.I. (2008). Behaviour and welfare in farmed fish. In Fish behaviour: 593-627. Magnhagen, C., Braithwaite, V.A., Forsgren, E. \& Kapoor, B.G. (Eds). Enfield: Science Publishers.

Brockmark, S. \& Johnsson, J.I. (2010). Reduced hatchery rearing density increases social dominance, postrelease growth, and survival in brown trout (Salmo trutta). Can. J. Fish Aquat. Sci. 67, 288-295.

Brockmark, S., Adriaenssens, B. \& Johnsson, J.I. (2010). Less is more: density influences the development of behavioural life skills in trout. Proc. R. Soc. B 277, 3035-3043.

Broglio, C., Rodriguez, F. \& Salas, C. (2003). Spatial cognition and its neural basis in teleost fishes. Fish Fish. 4, 247-255.

Brown, A.D., Sisneros, J.A., Jurasin, T., Nguyen, C. \& Coffin, A.B. (2013). Differences in lateral line morphology between hatchery- and wild-origin steelhead. PLOS ONE 8, e59162.

Campbell, J.M., Carter, P.A., Wheeler, P.A. \& Thorgaard, G.H. (2015). Aggressive behavior, brain size and domestication in clonal rainbow trout lines. Behav. Genet. 45, 245-254.

Chapman, B.B., Ward, A.J.W. \& Krause, J. (2008). Schooling and learning: early social environment predicts social learning ability in the guppy, Poecilia reticulata. Anim. Behav. 76, 923-929.

Chen, Y.-C., Harrison, P.W., Kotrschal, A., Kolm, N., Mank, J.E. \& Panula, P. (2015). Expression change in Angiopoietin1 underlies change in relative brain size in fish. Proc. R. Soc. B 26, 820-827.

Clarke, L.R., Cameron, W.A. \& Carmichael, R.W. (2013). Density effects on subyearling fall Chinook salmon during hatchery rearing in raceways with oxygen supplementation and after release. N. Am. J. Aquac. 75, 18-24.

Ebbesson, L.O.E. \& Braithwaite, V.A. (2012). Environmental effects on fish neural plasticity. J. Fish Biol. 81, 2151-2174.

Eifert, C., Farnworth, M., Schulz-Mirbach, T., Riesch, R., Bierbach, D., Klaus, S., Wurster, A., Tobler, M., Streit, B., Indy, J.R., Arias-Rodriguez, L. \& Plath, M. (2014). Brain size variation in extremophile fish: local adaptation versus phenotypic plasticity. J. Zool. 295, 143-153.

Ellis, T., North, B., Scott, A.P., Bromage, N.R., Porter, M. \& Gadd, D. (2002). The relationships between stocking density and welfare in farmed rainbow trout. J. Fish Biol. 61, 493531.

Fischer, S., Bessert-Nettelbeck, M., Kotrschal, A. \& Taborsky, B. (2015). Rearing-group size determines social competence and brain structure in a cooperatively breeding cichlid. Am. Nat. 186, 123-140.

Griffiths, S.W., Brockmark, S., Höjesjö, J. \& Johnsson, J.I. (2004). Coping with divided attention: the advantage of familiarity. Proc. R. Soc. B 271, 695-699.

Healy, S.D. \& Rowe, C. (2013). Costs and benefits of evolving a larger brain: doubts over the evidence that large brains lead to better cognition. Anim. Behav. 86, e1-e3.

Ito, H., Ishikawa, Y., Yoshimoto, M. \& Yamamoto, N. (2007). Diversity of brain morphology in teleosts: brain and ecological niche. Brain Behav. Evol. 69, 76-86.
Johnsson, J.I., Brockmark, S. \& Näslund, J. (2014). Environmental effects on behavioural development: consequences for fitness of captive-reared fishes in the wild. J. Fish Biol. 85, 1946-1971.

Jonsson, B. \& Jonsson, N. (2011). Ecology of Atlantic Salmon and brown trout: habitat as a template for life histories. Dordrecht: Springer Science+Business Media B.V.

Kavanagh, M. \& Olson, D.E. (2014). The effects of rearing density on growth, fin erosion, survival, and migration behavior of hatchery winter steelhead. N. Am. J. Aquac. 76, 37-41.

Kihslinger, R.L. \& Nevitt, G.A. (2006). Early rearing environment impacts cerebellar growth in juvenile salmon. J. Exp. Biol. 209, 504-509.

Kihslinger, R.L., Lema, S.C. \& Nevitt, G.A. (2006). Environmental rearing conditions produce forebrain differences in wild Chinook salmon Oncorhynchus tshawytscha. Comp. Biochem. Physiol. A Mol. Integr. Physiol. 145, 145-151.

Kolm, N., Gonzalez-Voyer, A., Brelin, D. \& Winberg, S. (2009). Evidence for small scale variation in the vertebrate brain: mating strategy and sex affect brain size and structure in wild brown trout (Salmo trutta). J. Evol. Biol. 22, 25242531.

Kotrschal, K., van Staaden, M.J. \& Huber, R. (1998). Fish brains: evolution and environmental relationships. Rev. Fish Biol. Fish 8, 373-408.

Kotrschal, A., Sundström, L.F., Brelin, D., Devlin, R.H. \& Kolm, N. (2012). Inside the heads of David and Goliath: environmental effects on brain morphology among wild and growth-enhanced coho salmon Oncorhynchus kisutch. J. Fish Biol. 81, 987-1002.

Kotrschal, A., Rogell, B., Bundsen, A., Svensson, B., Zajitschek, S., Brännström, I., Immler, S., Maklakov, A.A. \& Kolm, N. (2013). Artificial selection on relative brain size in the guppy reveals costs and benefits of evolving a larger brain. Curr. Biol. 23, 168-171.

Larsen, M.H., Johnsson, J.I., Näslund, J., Thomassen, S.T. \& Aarestrup, K. (2016). Reduced rearing density increases postrelease migration success of Atlantic salmon (Salmo salar) smolts. Can. J. Fish Aquat. Sci. 73, 804-810.

Lema, S.C., Hodges, M.J., Marchetti, M.P. \& Nevitt, G.A. (2005). Proliferation zones in the salmon telencephalon and evidence for environmental influence on proliferation rate. Comp. Biochem. Physiol. A 141, 327-335.

Marchetti, M.P. \& Nevitt, G.A. (2003). Effects of hatchery rearing on brain structures of rainbow trout, Oncorhynchus mykiss. Environ. Biol. Fishes 66, 9-14.

Mayer, I., Meager, J., Skjæraasen, J.E., Rodewald, P., Sverdrup, G. \& Fernö, A. (2011). Domestication causes rapid changes in heart and brain morphology in Atlantic cod (Gadus morhua). Environ. Biol. Fishes 92, 181-186.

McCormick, S.D. (2013) Smolt physiology and endocrinology. In Euryhaline fishes: 199-251. McCormick, S.D., Farell, A.P. \& Brauner, C.J. (Eds). Oxford: Academic Press. 
Meek, J. \& Nieuwenhuys, R. (1998). Holosteans and Teleosts. In The central nervous system of vertebrates, volume 2: 759-937. Nieuwenhuys, R., ten Donkelaar, H.J. \& Nicholson, C. (Eds). Heidelberg: Springer-Verlag.

Melnychuk, M.C., Korman, J., Hausch, S., Welch, D.W., McCubbing, D.J.F. \& Walters, C.J. (2014). Marine survival difference between wild and hatchery-reared steelhead trout determined during early downstream migration. Can. J. Fish Aquat. Sci. 71, 831-846.

Metcalfe, N.B. (1998). The interaction between behavior and physiology in determining life history patterns in Atlantic salmon (Salmo salar). Can. J. Fish Aquat. Sci. 55, 93-103.

Näslund, J. \& Johnsson, J.I. (2016). Environmental enrichment for fish in captive environments: effects of physical structures and substrates. Fish Fish. 17, 1-30.

Näslund, J., Aarestrup, K., Thomassen, S.T. \& Johnsson, J.I. (2012). Early enrichment effects on brain development in hatchery-reared Atlantic salmon (Salmo salar): no evidence for a critical period. Can. J. Fish Aquat. Sci. 69, 14811490.

Noreikiene, K., Herczeg, G., Gonda, A., Balázs, G., Husby, A. \& Merilä, J. (2015). Quantitative genetic analysis of brain size variation in sticklebacks: support for the mosaic model of brain evolution. Proc. R. Soc. B 282, 20151008.

Roberts, B.L., Dean, J.A. \& Paul, D.H. (2002). Cerebellar regulation of sensimotor activity in brown trout. Brain Behav. Evol. 60, 241-248.

Rodríguez, F., Broglio, C., Durán, E., Gómez, A. \& Salas, C. (2006). Neural mechanisms of learning in teleost fish. In Fish cognition and behavior: 243-277. Brown, C., Laland, K. \& Krause, J. (Eds). Oxford: Blackwell Publishing Ltd.
Rosengren, M., Kvingedal, E., Näslund, J., Johnsson, J.I. \& Sundell, K. (2016). Born to be wild: effects of rearing density and environmental enrichment on stress, welfare and smolt migration in hatchery reared Atlantic salmon. Can. J. Fish Aquat. Sci. doi: 10.1139/cjfas-2015-0515.

Salas, C., Broglio, C., Rodríguez, F., López, J.C., Portavella, M. \& Torres, B. (1996). Telencephalic ablation in goldfish impairs performance in a "spatial constancy" problem but not in a cued one. Behav. Brain Res. 79, 193-200.

Saloniemi, I., Jokikokko, E., Kallio-Nyberg, I., Jutila, E. \& Pasanen, P. (2004). Survival of reared and wild Atlantic salmon smolts: size matters more in bad years. ICES J. Mar. Sci. 61, 782-787.

Salvanes, A.G.V., Moberg, O., Ebbesson, L.O.E., Nilsen, O., Jensen, K.H. \& Braithwaite, V.A. (2013). Environmental enrichment promotes neural plasticity and cognitive ability in fish. Proc. R. Soc. B 280, 20131331.

Schuck, H.A. (1948). Survival of hatchery trout in streams and possible methods of improving the quality of hatchery trout. Prog. Fish-Cult. 10, 3-14.

Shumway, C.A. (2008). Habitat complexity, brain, and behavior. Brain Behav. Evol. 72, 123-134.

Striedter, G.F. (2005). Principles of brain evolution. Sunderland: Sinauer Associates Inc.

Thorpe, J.E. (1977). Bimodal distribution of length of juvenile Atlantic salmon (Salmo salar L.) under artificial rearing conditions. J. Fish Biol. 11, 175-184.

Wiper, M.L., Britton, S. \& Higgs, D.M. (2014). Early experience and reproductive morph both affect brain morphology in adult male Chinook salmon (Oncorhynchus tshawytscha). Can. J. Fish Aquat. Sci. 71, 1430-1436. 